\title{
CORRECTION
}

\section{Correction to: Results of Cerchar, LCPC, and equivalent quartz content from rolling indentation abrasion testing in plutonic rock}

\author{
Masih Moradizadeh ${ }^{1} \cdot$ Akbar Cheshomi $^{1}$
}

Published online: 8 July 2021

○) Springer-Verlag GmbH Germany, part of Springer Nature 2021

\section{Correction to: Bulletin of Engineering Geology and the Environment (2021) \\ https://doi.org/10.1007/s10064-021-02335-x}

The authors would like to correct Eq. 11 which was written wrongly. Below is the corrected expression.

$A P R=0.145 E Q C^{2}-16.095 E Q C+453.188 R^{2}=0.95$.

The original article has been corrected.

The original article can be found online at https://doi.org/10.1007/ s10064-021-02335-x.

Akbar Cheshomi

a.cheshomi@ut.ac.ir

1 Department of Structural and Engineering Geology, School of Geology, College of Sciences, University of Tehran, Tehran, Iran 